\title{
FUNDIÇÃO SQUEEZE CAST: CONSTRUÇÃO DE UMA BANCADA DIDÁTICA UTILIZANDO UM MOTOR DE FUSCA
}

Lisiane Trevisan - lisiane.trevisan@farroupilha.ifrs.edu.br

Instituto Federal de Educação, Ciência e Tecnologia do Rio Grande do Sul-IFRS - Campus Farroupilha

Av. São Vicente, 785 - Bairro Cinquentenário

95180-000 - Farroupilha - Rio Grande do Sul

Júlio César Almeida Mientkewicz - juliomientk@hotmail.com

Instituto Federal de Educação, Ciência e Tecnologia do Rio Grande do Sul - IFRS - Campus Farroupilha

Av. São Vicente, 785 - Bairro Cinquentenário

95180-000 - Farroupilha - Rio Grande do Sul

Daniel Antonio Kapper Fabricio - danielkapper@gmail.com

Instituto Federal de Educação, Ciência e Tecnologia de Santa Catarina - IFSC - Campus Chapecó

Avenida Nereu Ramos, 3450-D - Barro Seminário

89813-000 - Chapecó - Santa Catarina

Vinicius de Freitas Paz-vinicius.paz@farroupilha.ifrs.edu.br

Instituto Federal de Educação, Ciência e Tecnologia do Rio Grande do Sul - IFRS - Campus Farroupilha

Av. São Vicente, 785 - Bairro Cinquentenário

95180-000 - Farroupilha - Rio Grande do Sul

Resumo: A construção de bancadas didáticas com a utilização de componentes industriais mostra-se uma promissora área de estudo e de aprendizagem na engenharia. Este trabalho tem como objetivo construir uma injetora squeeze cast para ligas de zinco com componentes do motor automotivo refrigerado a ar, como motores usados em fuscas. A metodologia está focada no aproveitamento da movimentação do sistema de pistões/virabrequim dentro da câmara de combustão para que o mesmo fosse utilizado para a preenchimento do metal líquido na primeira etapa da injeção do metal líquido. O sistema utiliza a força humana para a movimentação do sistema. Os resultados obtidos no primeiro ensaio mostram que foi possível realizar o preenchimento da matriz metálica e solidificação do zinco fundido dentro da matriz. metálica. Melhorias no sistema de escape de gás, sistema de desmoldagem e no aquecimento da matriz podem ser realizados futuramente.

Palavras-chave: Fundição. Educação para engenharia. Metalurgia.

\section{INTRODUÇÃO}

Segundo Moran (2015), as escolas estão mudando para modelos mais centrados em aprender ativamente com problemas reais, desafios relevantes, jogos, atividades e leituras, 
valores fundamentais, combinando tempos individuais e tempos coletivos; projetos pessoais de vida e de aprendizagem e projetos em grupo. A tendência é priorizar o envolvimento maior do aluno, com metodologias ativas como o ensino por projetos de forma mais interdisciplinar, o ensino híbrido e a sala de aula invertida.

Partindo destas percepções iniciais, sabe-se que o processo de fundição e suas características compõem a ementa de vários componentes curriculares para diferentes cursos de graduação, especialmente engenharia metalúrgica e engenharia mecânica. A demonstração prática dos diferentes processos de fundição mostra-se um desafio para o docente. Além da limitação de espaço físico das universidades para compor todas os equipamentos necessários, há a limitação financeira para a aquisição destes equipamentos pelas universidades.

O desafio instigado aos alunos seria a construção de uma injetora com partes de motores automotivos, usando o princípio do movimento dos pistões dentro do bloco de motor de motores a combustão. $\mathrm{O}$ uso dos motores automotivos foi usado devido à paixão por carros por parte dos alunos envolvidos e, envolver também a temática do reaproveitamento de materiais e equipamentos para outras funções, como por exemplo produção de componentes metálicos. Assim, o objetivo deste trabalho é construir um equipamento que mostre didaticamente o processo de fundição Squeeze Cast, incluindo o vazamento e o processo de resfriamento.

Este projeto posteriormente será usado dentro das aulas que tratarem do processo de fundição, assunto tratado em diversos componentes curriculares do curso técnico em metalurgia do campus Farroupilha do Instituto Federal de Educação, Ciência e Tecnologia do Rio Grande do Sul (IFRS).

\section{REFERENCIAL TEÓRICO}

\subsection{Processo de fundição sob pressão}

Entende-se por fundição, o processo onde uma liga fundida é vazada ou injetada sob pressão em um molde onde essa liga se solidifica no formato da cavidade do molde. Esse método é utilizado para fabricar diversas peças de liga de alumínio (pistões de motores), de aços (turbinas de hidroelétricas), de ferro fundido (blocos de motores), e outras (KIMINAMI, 2013).

$\mathrm{Na}$ fundição sob pressão, o material fundido é vazado sob pressão em uma matriz, garantindo seu total preenchimento. Esse molde geralmente é confeccionado em açoferramenta, sendo refrigerado a água e é constituído de componentes que toleram seu fechamento e abertura (KIMINAMI, 2013).

Um exemplo de processo de fundição sob pressão é o squeeze casting, um processo híbrido em que ocorre a combinação entre fundição de baixa pressão e alta pressão, baixa pressão devido a pressão de injeção e as características de alta pressão estão ligas à capacidade de 
eliminar gases apreendidos (POWELL et al., 2012). A figura 1 mostra as etapas de preenchimento e solidificação do processo Squeeze Cast.

Figura 1 - Exemplificação do processo Squezze casting de fundição e suas etapas, como referência para realização do projeto. (FILHO, 2017)

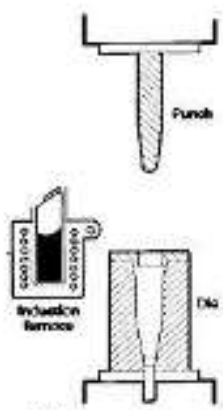

(a)

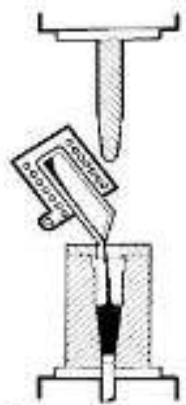

(b)

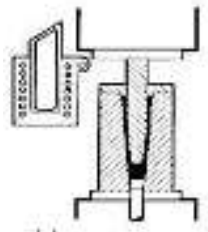

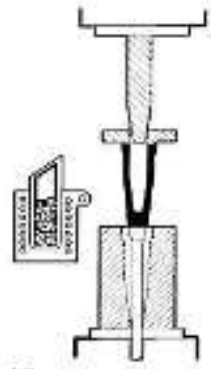

(c)

O processo de squeeze casting pode produzir componentes metálicos com uma microestrutura refinada, isso porque há um controle do sistema de resfriamento do molde. Em alguns casos, as propriedades mecânicas se assemelham a peças forjadas (KRIDLI et al., 2010).

Como em outros processos de fabricação, podemos citar algumas vantagens da fundição sob pressão, como: a possibilidade da produção de peças com formas complexas, a alta capacidade de produção, a alta durabilidade das matrizes, peças com maior resistência em comparação as fundidas em areia; porém, a limitação do emprego da técnica a ligas não ferrosas, a limitação do peso das peças (raramente superior a cinco quilos), o alto custo do equipamento assim como sua manutenção, podem ser citados como desvantagens do método de fundição sob pressão (BALDAM, 2014).

METODOLOGIA

A partir da percepção da importância das vivências práticas nos espaços acadêmicos, como forma complementar dos processos de ensino e aprendizagem, a presente pesquisa se propõe pensar: "É possível fabricar uma injetora de fundição sob pressão para metais fundidos, utilizando materiais alternativos, sem gerar qualquer custo de produção, e reciclar materiais?"

Para tanto, a construção deste maquinário foi pensada com o uso de elementos mecânicos de motores, tubos e chapas de aço, entre outros, materiais alternativos que não gerassem custos à instituição, colaborando ainda com o reuso de materiais que, a priori, seriam descartados.

O material metálico escolhido para a fusão foi o Zamac, uma liga metálica composta de zinco, com adição de outros metais como alumínio, magnésio e cobre, onde, as propriedades desses aditivos se completam quando fundidos para a confecção do mesmo (CARVALHO E PORTUGAL, 2006). O Zamac foi escolhido pela menor temperatura de fusão e sua disponibilidade dentro do ambiente escolar.

Para a construção da injetora foram reutilizadas peças de motores de automóveis, partes essas recebidas através de doações, em sua maioria. Como partes principais, cita-se a utilização 
do pistão e da camisa de pistão de um automóvel modelo fusca, assim como virabrequim, biela e bronzinas provenientes de um motor aspirado do fabricante Volkswagen, e um volante motor de marca desconhecida.

O motor de fusca, sendo um motor refrigerado a ar, possui o virabrequim horizontal no centro do bloco com cilindros opostos, esses são contornados por aletas que servem para ter uma maior transferência de calor e realizar a refrigeração do cilindro durante a combustão. (TILLMANN, 2013).

\section{RESULTADOS}

Para a construção da injetora, o projeto foi dividido em 3 etapas principais. Primeiro foi a construção da injetora através do software SolidWorks, onde foi possível verificar o sistema de construção do equipamento, com as suas partes. Na segunda parte, o motor automotivo foi então desmembrado e adaptações foram necessárias e realizadas com uso dos processos de soldagem e usinagem. E por fim, foram realizados os testes com o equipamento construído no laboratório de fundição do Instituto Federal do Rio Grande do Sul - IFRS Campus Farroupilha.

\subsection{Projeto}

O projeto foi inicialmente realizado sua construção no software SolidWorks para a verificação dos componentes necessários e suas movimentações. A Figura 2 mostra o projeto da injetora e nela não está incluída a fixação da matriz metálica no sistema.

A injetora foi projetada para ter um acionamento totalmente mecânico, conforme a figura 2 , está presente uma manivela, sem conter elementos elétricos em seu desenvolvimento. $\mathrm{O}$ acionamento manual está focado na facilidade de construção. Neste equipamento, o material metálico será vazado manualmente através de um cadinho.

Figura 2 - Desenho do projeto didático considerando os componentes automotivos: pistão, virabrequim, biela e cilindro.

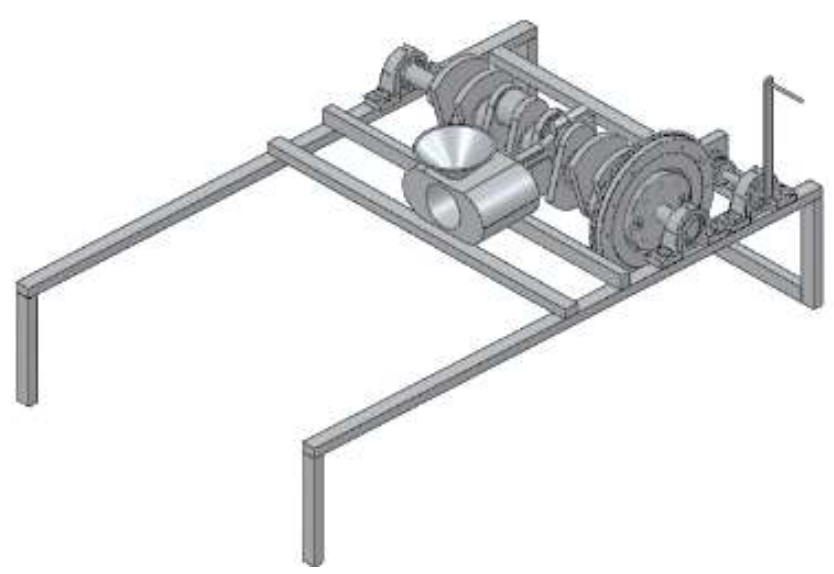

Fonte: Autores.

Sobre o funcionamento da injetora, pode-se especificar que após vazar o material fundido no canal de alimentação, é acionada a manivela que irá movimentar as engrenagens deslocando 
o virabrequim e consequentemente o pistão do motor. Com esse movimento, o Zamac é injetado para dentro da matriz, onde o material se solidificará na forma da cavidade da matriz metálica.

\subsection{Motor Aspirado e suas adaptações}

Para a compatibilização da biela de motor automotivo aspirado, com o pistão de fusca, foi necessário usinar uma bucha nova em um torno mecânico. Após a usinagem, a biela foi cortada e foi realizado o processo de soldagem dessa bucha na biela, tornando assim possível o encaixe das peças, conforme a Figura 3.

Figura 3 - Demonstração da adaptação da biela soldada na bucha usinada.

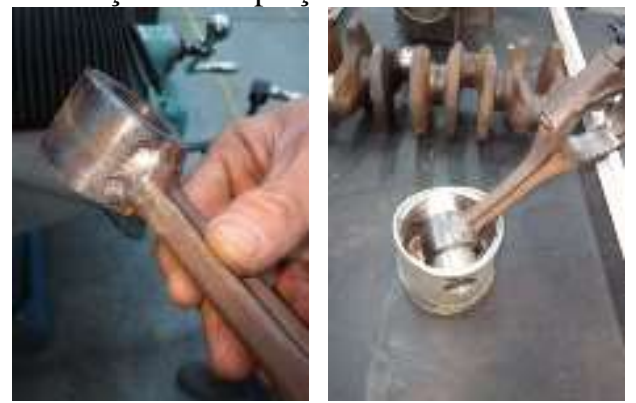

Fonte: Autores

Para a camisa de pistão foi realizado o processo de fresamento, a fim de remover as aletas de resfriamento. Esta etapa foi realizada para que fosse possível a fixação da mesma na estrutura da máquina. Com a face da camisa fresada conforme a Figura 4, foi realizada a furação na parte superior para acoplar um funil, peça essa que terá a função do canal de alimentação da matriz metálica, constituída pelo cilindro onde o pistão de movimenta.

Na Figura 4, pode-se observar o desenho técnico da redução concêntrica, que foi realizado em uma chapa de aço, e logo após dobrada para dar a forma desejada. Esta redução será adaptada para que possa realizar o vazamento do Zamac líquido. Sendo assim, peça já em sua geometria, onde foi devidamente soldada através do processo TIG, e acoplada na camisa de pistão através do método de soldagem MIG.

Figura 4 - Desenho da redução concêntrica (funil de descida) e na figura à direita, camisa do pistão com o funil

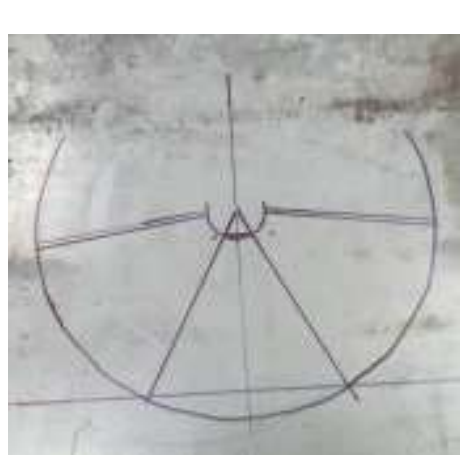
acoplado.

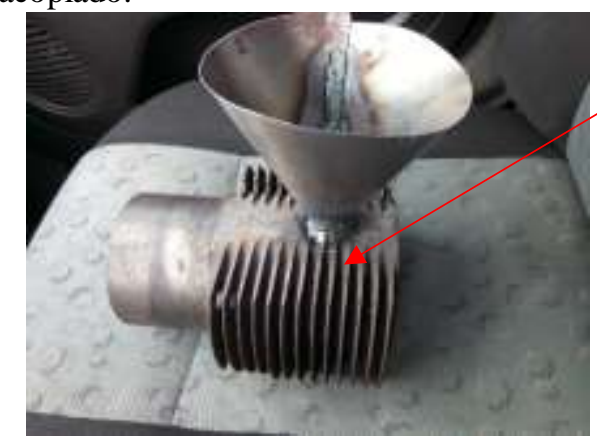

Camisa de cilindro

fresada e com o funil já unido por soldagem, para realizar a função do canal de descida (funil) e da matriz metálica (cilindro do motor).

Fonte: Autores.

Em um torno mecânico, foram usinadas as pontas de eixo, soldadas através do processo de solda TIG nas extremidades do virabrequim, sendo demonstrado na figura 5. Foram também 
usinados mancais para fixação dos rolamentos, que por sua vez são fixados na ponta de eixo do virabrequim.

Figura 5 - Ponta de eixo usinada e posteriormente soldada (figura a direita).

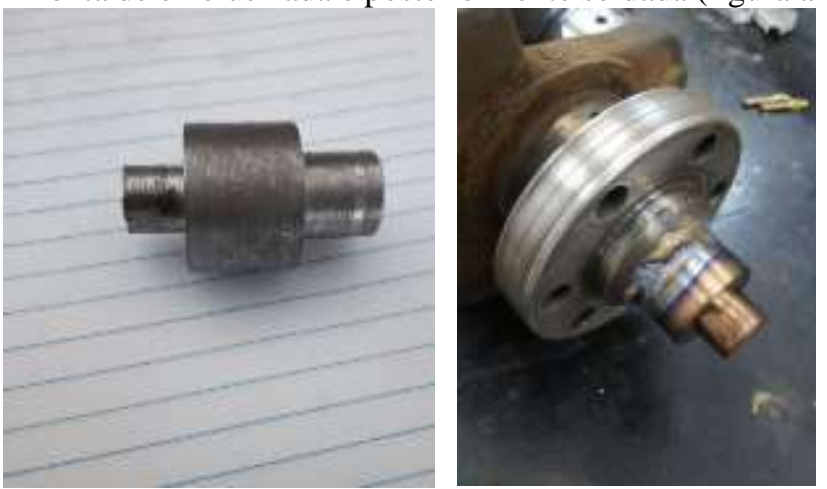

Fonte: Autores.

Após a usinagem de todas as peças necessárias, foi dado início ao processo de construção da máquina, onde durante a montagem da mesma, foram realizadas modificações na estrutura, reduzindo assim suas dimensões. Para a pintura da injetora, foram definas as cores azul para as partes móveis e acabamentos, enquanto as partes fixas da estrutura foram pintadas de branco. Esses processos podem ser observados na figura 6.

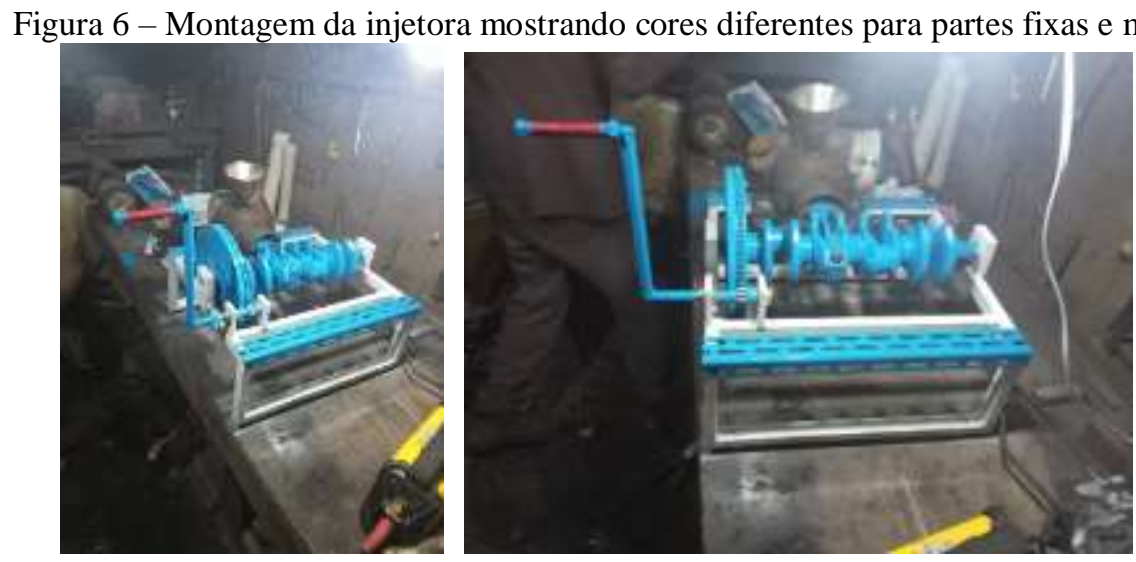

Fonte: Autores

\subsection{Ensaios}

Com a construção da injetora concluída, foram iniciados os testes para a verificação da sua funcionalidade. A primeira etapa está voltada para a fusão do material metálico que foi realizado em um cadinho de grafite, no forno de tratamento térmico.

$\mathrm{O}$ Zamac foi aquecido em forno de resistência elétrica em cadinho a temperatura em torno de $420^{\circ} \mathrm{C}$ durante 1 hora, aproximadamente. Em conjunto com a etapa de fusão do ZAMAC, utilizou-se um maçarico para aquecer a camisa de pistão, que neste projeto assumiu a função do canal de descida para a injeção. O objetivo deste pré-aquecimento está em reduzir o delta de temperatura entre o metal fundido e a matriz metálica, durante o vazamento do metal liquido a 
matriz (Camisa do pistão), evitando assim a solidificação do metal líquido ao entrar em contato com a mesma (Figura 8).

É importante destacar que, para realização de tais processos, utilizou-se vestimenta e equipamentos para proteção individual, a fim de evitar qualquer acidente, como é demonstrado na figura 7.

Figura 7 - Aquecimento do sistema de alimentação da injetora. À direita mostra equipamentos de proteção individual para os alunos envolvidos.
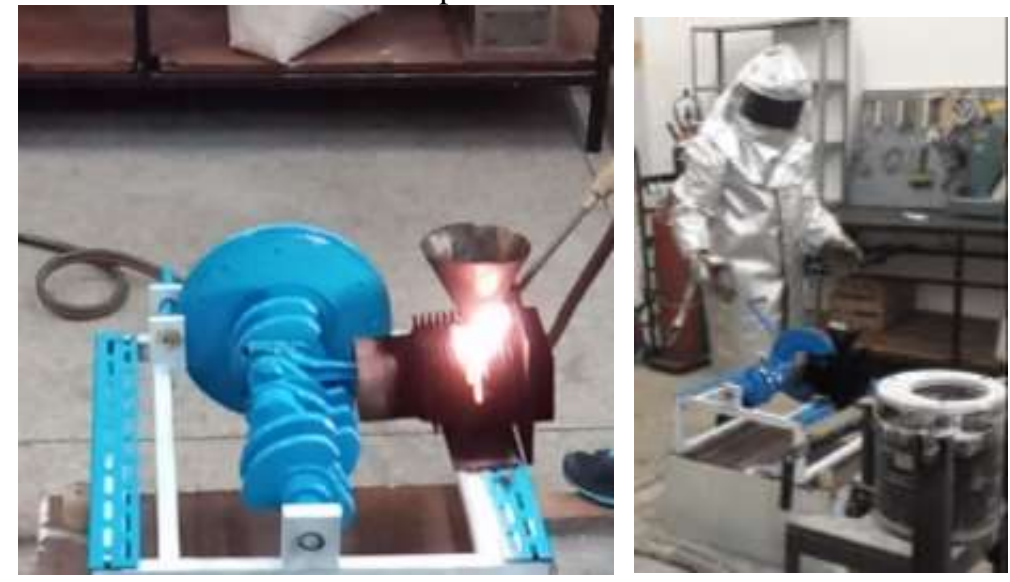

Fonte: Autores.

Após o vazamento do Zamac, utilizou-se a manivela para que a movimentação do pistão permitisse o desclocamento do metal líquido para dentro da matriz metálica e assim preencher a mesma.

Posterior a etapa de preenchimento da matriz (cilindro do pistão) com ZAMAC, foi necessário aguardar o tempo de solidificação do metal líquido para posterior remoção da matriz, revelando a peça injetada em suas formas pré-definidas, como pode-se observar na figura 8 . Referente à matriz, foi projetada uma matriz metálica predefinida com a cavidade em forma de um automóvel fusca, como demonstrado na figura 8, como alusão ao sistema construído.

Figura 8 - Matriz metálica à esquerda. À direita, matriz preenchida com a liga escolhida para o desenvolvimento deste projeto

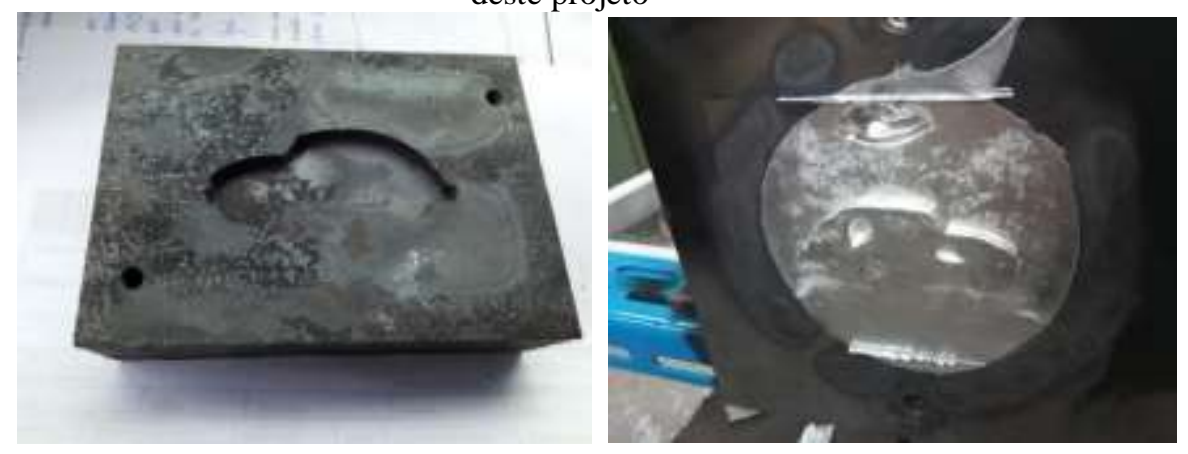

Fonte: Autores.

Conforme verificado na Figura 8, observa-se alguns defeitos como aprisionamento de gases e bolhas no componente injetado. Muito provavelmente esse defeito deve-se ao aprisionamento de ar dentro da matriz metálica, qual apresenta-se ineficiente na versão inicial 
do protótipo de injeção Squeze cast, projetado em conjunto com os alunos dos Cursos técnicos e Engenharia.

Nesse sentido observa-se que o protótipo projetado dentro da instituição requer melhorias e otimizações de projeto, para que possa ser utilizado como material lúdico e equipamento laboratorial para as aulas dos cursos técnicos em Metalurgia e de Engenharia Mecânica.

Ressalta-se também que poderão ser realizadas novas adaptações dentro do sistema para uso de outras matrizes metálicas para componentes com pequena massa metálica.

\section{CONSIDERAÇÕES FINAIS}

De um modo geral, a metodologia aplicada à turma de Processos Metalúrgicos do curso técnico em metalurgia do Instituto Federal de Educação, Ciência e Tecnologia do Rio Grande do Sul - Campus Farroupilha apresentou-se satisfatória, dentro do planejado.

Durante o processo de construção da injetora, foram encontradas algumas dificuldades técnicas na fase de execução do projeto, que por sua vez resultaram no atraso da confecção do mesmo. Entre as dificuldades encontradas, pode-se citar a escassez de ferramentaria, assim como o maquinário, por vezes estava indisponível para o uso prático. Dentre outros problemas, também é possível mencionar a falta de conhecimento em usinagem, necessitando em muitas vezes o requerimento de auxílio técnico, o que em contrapartida possibilitou aproximação e experiência com alguns processos como torneamento, fresamento e soldagem, ou seja, outras áreas de processos de fabricação diversificando o conhecimento técnico adquirido ao final do trabalho.

Com a realização de alguns testes, foi possível comprovar que o desafio proposto no início do projeto de construir uma injetora squeeze cast em Zamac utilizando materiais inicialmente destinados a outras funções, é realmente possível, mesmo sendo necessário algumas adaptações. Algumas melhorias precisam ser realizadas para que obtida uma peça injetada com total preenchimento, isenta de defeitos. No entanto, como o objetivo encontra-se na demonstração do processo de fundição squeeze cast, ou seja, para fins didáticos, encontra-se dentro do esperado e satisfatório, no qual foi possível utilizar um sistema mecânico de um motor automotivo, para demonstrar um processo de fundição de baixa pressão e elevadas propriedades mecânicas finais do material produzido pelo mesmo.

Busca-se nos próximos trabalhos, implementar algumas melhorias, como o aquecimento do canal de alimentação da injetora, e até mesmo um motor elétrico para seu acionamento, ao invés de uma manivela, também poderia ser modificado o canal de alimentação para que a remoção da peça pronta fosse facilitada.

Destaca-se a importância do desenvolvimento deste projeto quando observada a interdisciplinaridade, tendo sido aplicados conceitos de vários outros componentes curriculares para o seu desenvolvimento: fundição (principalmente) e também conceitos de soldagem, usinagem, motores a combustão, desenho técnico entre outros.

É importante que a interdisciplinaridade com outras disciplinas do curso de engenharia mecânica, assim podendo mostrar a aplicação de conceitos não só dentro da própria disciplina, mas em outras áreas de abrangência do curso.

\section{REFERÊNCIAS}

BALDAM, R. L.; VIEIRA, E. A. Fundição: Tecnologias e técnicas correlatas. Editora Érica. $1^{\circ}$ edição, 2013. 
CARVALHO, E. G.; PORTUGAL, N. S. Desenvolvimento de produtos em Zamac: uma proposta de utilização do diagrama sistemático para definição de ações preventivas. In: XIII Simpósio de Engenharia de Produção - SIMPEP. Bauru, São Paulo, 2006. Disponível em: < http://docplayer.com.br/31562889-Desenvolvimento-de-produtos-em-zamac-uma-propostade-utilizacao-do-diagrama-sistematico-para-definicao-de-acoes-preventivas.html> Acesso em: 22 jun 2019.

FILHO, R. M. O. Correlações entre parâmetros estruturais e microdureza em ligas Al-SiCu obtidas através do processo Squeeze Casting, Dissertação de Mestrado no programa de Pós-Graduação em Ciência dos Materiais PPGEM da UFP, 2017.

KIMINAMI, C. S. Introdução aos processos de fabricação de produtos metálicos. São Paulo: Blucher, 2013.

KRIDLI, G. T.; FRIEDMAN, P. A.; BOILEAU, J. M. Materials, Design and Manufacturing for Lightweight Vehicles. Manufacturing processes for light alloys. 2010, Pages 235-274.

MORAN, J. Mudando a educação com metodologias ativas. Coleção Mídias Contemporâneas, v. II, 2015.

POWELL, B. R.; LUO, A. A.; KRAJEWSKI, P. E. Magnesium alloys for lightweight powertrains and automotive bodies. Advanced Materials in Automotive Engineering. 2012, Pages 150-209.

TILLMAN, C. A. C. Motores de combustão interna e seus sistemas. Pelotas: Instituto Federal de Educação, Ciência e Tecnologia; Santa Maria: Universidade Federal de Santa Maria, Colégio Técnico Industrial de Santa Maria; Rede e-Tec Brasil, 2013.

\section{SQUEEZE CAST FOUNDRY: BUILDING A TEACHING STAND USING A FUSION ENGINE}

Abstract: The construction of didactic benches using industrial components is a promising area for study and learning in engineering. This work aims to build a squeeze cast injector for zinc alloys with air-cooled automotive engine components, such as engines used in beetles. The methodology is focused on taking advantage of the movement of the piston / crankshaft system inside the combustion chamber so that it could be used to fill the liquid metal in the first stage of the injection of the liquid metal. The system uses human force to move the system. The results obtained in the first test show that it was possible to complete the metallic matrix and solidify the molten zinc within the metallic matrix. Improvements to the gas exhaust system, demoulding system and matrix heating can be made in the future.

Keywords: Foundry. Engineering education. Metallurgy. 